\title{
0 processo de análise de demandas por regulamentação técnica metrológica e a evolução das práticas de avaliação no Inmetro
}

Ligia Gomes Elliot ${ }^{1}$

Raquel Martins Rêgo ${ }^{2}$

Taiana Fortunato Araújo ${ }^{3}$ Rita de Cássia Pires Reis Silva ${ }^{4}$

Marcelo Castilho de Freitas ${ }^{5}$ Letícia Bispo Joaquim Atanásio ${ }^{6}$

1 Ph.D em Educação/Avaliação pela Universidade da Califórnia. Coordenadora do Curso de Mestrado Profissional em Avaliação do Programa de Pós-graduação da Fundação Cesgranrio e pesquisadora do Centro de Avaliação.

2 Graduada em História pela Universidade do Estado do Rio de Janeiro (UERJ). Analista executiva em metrologia e qualidade do Instituto Nacional de Metrologia, Qualidade e Tecnologia (Inmetro).

3 Mestre em Economia pelo Universidade Federal de Minas Gerais (UFMG). Analista da área de ciências econômicas do Instituto Nacional de Metrologia, Qualidade e Tecnologia (Inmetro).

4 Inmetro.

5 Mestre em Engenharia Metalúrgica e de Materiais pela Universidade Federal do Rio de Janeiro (UFRJ). Pesquisador-tecnologista do Instituto Nacional de Metrologia, Qualidade e Tecnologia (Inmetro).

6 Inmetro. 
O PRESENTE ARTIGO É UM ESTUDO DE CASO SOBRE A EVOLUÇÃO DAS PRÁTICAS DE AVALIAÇÃO ADOTADAS PELO INSTITUTO NaCional de Metrologia, Qualidade E TECNOLOGIA (INMETRO) NA ANÁLISE DE DEMANDAS POR REGULAMENTAÇÃO TÉCNICA METROLÓGICA. O ARTIGO DISCORRE SOBRE AS PRINCIPAIS METODOLOGIAS UTILIZADAS, SUA ABORDAGEM E OUTRAS CLASSIFICAçÕES DE ACORDO COM A LITERATURA EM AVALIAÇÃO DE PROGRAMAS. SÃO APRESENTADOS OS PRINCIPAIS RESULTADOS E USOS DA AVALIAÇÃO, ENFATIZANDO SUA IMPORTÂNCIA NO APOIO À TOMADA DE DECISÃO DA ADMINISTRAÇÃO.

\section{Abstract}

THE PRESENT ARTICLE IS A CASE STUDY ON THE EVOLUTION OF EVALUATION PRACTICES ADOPTED BY THE NATIONal INSTITUTE OF METRology, QUality AND TECHNOLOGY (INMETRO) IN THE ANALYSIS OF DEMANDS FOR LEGAL METROLOGY REGULATION. THE ARTICLE DISCUSSES THE MAIN METHODOLOGIES USED, THE APPROACH AND OTHER CLASSIFICATIONS ACCORDING TO THE LITERATURE on Program Evaluation. The main Results and USES OF EVALUATION ARE PRESENTED, AND ITS IMPORTANCE IN SUPPORTING THE DECISION MAKING OF MANAGEMENT IS EMPHASIZED.

\section{PALAVRAS-CHAVE:}

Avaliação; Avaliação ex-ante; Gestão pública; Regulamentação técnica metrológica.

Revista Brasileira de Monitoramento e Avaliação | Número 9 | Janeiro-Junho de 2015

0 processo de análise de demandas por regulamentação técnica metrológica e a evolução das práticas de avaliação no Inmetro 


\section{Introdução}

O Instituto Nacional de Metrologia, Qualidade e Tecnologia (Inmetro) é uma autarquia federal, vinculada ao Ministério do Desenvolvimento, Indústria e Comércio Exterior (MDIC), que tem como missão "[...] prover confiança à sociedade brasileira nas medições e nos produtos, através da metrologia e da avaliação da conformidade, promovendo a harmonização das relações de consumo, a inovação e a competitividade do país" (INMETRO, [s.d]).

A confiança nas medições e nos produtos é atestada pelo Inmetro por meio da execução e supervisão de diversas atividades no âmbito da metrologia legal, da metrologia científica e industrial, da avaliação da conformidade e da acreditação, realizadas diretamente pelo instituto ou por órgãos delegados?

A metrologia legal é uma área de conhecimento que se refere às medições, unidades de medida, instrumentos e métodos de medição cujos requisitos tenham sido definidos em regulamentação específica, aprovada por ato normativo. Engloba os produtos pré-medidos (medidos e embalados sem a presença do consumidor e colocados posteriormente à venda) e os instrumentos de medição utilizados em transações comerciais, na área da saúde, da segurança e do meio ambiente.

No campo da metrologia legal, o Inmetro tem como objetivos assegurar a credibilidade dos resultados das medições dos instrumentos de medição regulamentados e realizar o controle da indicação quantitativa e do conteúdo dos produtos pré-medidos. Essa credibilidade é demandada especialmente nos casos em que há assimetria de informação, sendo necessária a intervenção de um árbitro imparcial. Além disso, responde à necessidade de proteger tanto o comprador como o vendedor em uma transação comercial ou de atuar quando os resultados das medições são usados para a aplicação de alguma penalidade (INTERNATIONAL ORGANIZATION OF LEGAL METROLOGY, 2012).

Dessa forma, cabe ao Estado ocupar a posição de arbitragem.

O consumidor raramente pode identificar a má qualidade de um produto ou serviço no momento de sua aquisição e conta com o Estado para sua proteção. Consequentemente, o governo não só tem o direito, mas, também, o dever de intervir na comercialização desses bens e serviços. Essa intervenção determina e controla os atributos técnicos de produtos ou serviços tomando a forma da legislação, denominada regulamentação técnica. (SILVA, 2007, p. 36).

De acordo com a Organização Internacional de Metrologia Legal (OIML), a manutenção de uma estrutura regulatória e de law enforcement (aplicação da lei) em metrologia traz diversos benefícios para a sociedade, tais como redução de custos e disputas nas transações comerciais, uma vez que há confiança nos resultados das medições; proteção do consumidor; controle de fraudes; condições de concorrência equitativas para o comércio; e controle efetivo do estoque de produtos (IN- 
TERNATIONAL ORGANIZATION OF LEGAL METROLOGY, 2003). Além das questões econômicas, a estrutura regulatória e a aplicação da lei nas medições realizadas na área da saúde, da segurança e do meio ambiente também acarretam benefícios para a população.

No Brasil, cabe ao Inmetro a responsabilidade pela estrutura regulatória e de law enforcement em metrologia. Os regulamentos técnicos metrológicos definem requisitos a serem observados em todo o território nacional por diversos segmentos da economia, como fabricantes e importadores de instrumentos de medição, indústria alimentícia, comércio, entre outros. Além de elaborar a regulamentação técnica metrológica, o Inmetro é responsável pelo controle metrológico legal, que é composto pelas seguintes atividades: controle legal dos instrumentos de medição, supervisão metrológica e perícia metrológica (INMETRO, 2007).

O controle legal dos instrumentos de medição abrange a aprovação de modelo e as verificações, que são processos de controle prévio e a posteriori desses produtos no mercado, de acordo com os regulamentos específicos.
Essas atividades são realizadas mediante o pagamento de taxas definidas em lei (BRASIL, 1999).

0 regulamento pode estabelecer que 0 Inmetro aprove o modelo do instrumento de medição, a fim de atestar sua conformidade aos requisitos. A aprovação é solicitada geralmente pelo fabricante ou importador do instrumento de medição, que é seu responsável legal. Caso seja aprovado, o Inmetro publica portaria de aprovação de modelo no Diário Oficial da União e a disponibiliza no sítio da instituição.

Outro mecanismo de controle prévio é a verificação inicial, que consiste em exame e ensaios realizados nos instrumentos de medição antes de sua colocação no mercado. Essa atividade pode ser realizada em todas as unidades do instrumento ou por amostragem, e é executada pelos órgãos delegados e pelas superintendências do Inmetro nos estados.

Após sua colocação no mercado, se o regulamento assim definir, o instrumento de medição pode ser submetido a verificações subse-

7 O Inmetro atua por meio de um modelo descentralizado, com a delegação de atividades nas áreas de metrologia legal e avaliação da conformidade a institutos de metrologia e qualidade, conhecidos como institutos de pesos e medidas. Esses órgãos fazem parte da Rede Brasileira de Metrologia Legal e Qualidade-Inmetro (RBMLO-I), que possui 23 órgãos estaduais, um órgão municipal e duas superintendências do Inmetro, conforme informações obtidas no sítio da instituição. <http://www.inmetro.gov.br/>.

Revista Brasileira de Monitoramento e Avaliação | Número 9 | Janeiro-Junho de 2015 
quentes, realizadas periodicamente ou após manutenção e reparo do instrumento. Essa tarefa também é feita pelos órgãos delegados do Inmetro e suas superintendências nos estados. As verificações subsequentes são mecanismos de controle a posteriori. Nessa etapa, o responsável legal pelo instrumento de medição é o seu detentor (por exemplo, um estabelecimento comercial), que pode ser penalizado em caso de não conformidade às exigências regulamentares.

Além do controle legal dos instrumentos de medição, o Inmetro realiza a supervisão metrológica, que compreende atividades como as vigilâncias de campo, de mercado e do sistema da qualidade, que buscam determinar se os instrumentos de medição, as medições e os produtos pré-medidos estão em conformidade com a legislação metrológica (INTERNATIONAL ORGANIZATION OF LEGAL METROLOGY, 2004) $)^{8}$.

Como se pode perceber, os mecanismos de controle em metrologia legal implicam custos para todos os envolvidos, inclusive para o Estado, que devem ser suplantados pelos benefícios esperados com a regulamentação. Tendo em vista esses custos e os impactos da regulamentação na sociedade, o Inmetro utiliza ferramentas para avaliar a necessidade e a pertinência de sua atuação em cada caso. Essa avaliação é denominada análise de demandas por regulamentação técnica metrológica.
O processo de análise de demandas é iniciado com a identificação de problemas no campo da metrologia legal que possam ser solucionados ou minimizados pelo controle metrológico legal. Tais problemas podem ser detectados internamente, por especialistas do Inmetro, de suas superintendências e dos órgãos delegados, ou externamente, por meio de denúncias e consultas recebidas de diversos segmentos da sociedade, como associações civis, fabricantes, órgãos de governo e setor produtivo, dentre outros. 0 processo tem como objetivo julgar o mérito e o impacto de cada demanda, fornecendo informações úteis à Diretoria de Metrologia Legal para a tomada de decisões quanto à regulamentação.

As análises envolvem mecanismos de avaliação quantitativos e qualitativos, que enfatizam a participação da sociedade diretamente por meio de pesquisas de opinião e de painéis setoriais. Nos casos em que o Inmetro decide elaborar regulamento técnico metrológico, a participação das partes interessadas e impactadas pela regulamentação (stakeholders) continua nas demais etapas do processo: no desenvolvimento do regulamento em si, em comissões técnicas consultivas que discutem os requisitos propostos pelo Inmetro; e na implementação da regulamentação, em reuniões que definem como esses requisitos serão cumpridos pela sociedade em geral.

Ao final do processo de análise de demandas, é elaborado um relatório com os resultados da avaliação e recomendações para a diretoria. 
O presente artigo tem como objetivo apresentar a evolução dessas práticas de avaliação no Inmetro, ressaltando seu papel como indutoras de mudanças no processo de regulamentação técnica metrológica e na gestão da instituição.

\section{Metodologia}

O estudo de caso foi a metodologia selecionada para proceder à progressiva apresentação das práticas de avaliação adotadas pelo Inmetro. Tal escolha se apoiou em autores reconhecidos nesse tema.

Segundo Alves-Mazzotti (2006), os estudos de caso têm como foco uma unidade: um indivíduo, uma instituição, um grupo de pessoas ou um evento. No entanto, devem ser situados na discussão acadêmica mais ampla do objeto, recorrendo ao contexto e à história para a interpretação dos dados obtidos.

A literatura apresenta diferentes tipologias de estudos de caso, que interessam aos estudiosos de metodologias avaliativas e de pesquisa. Dentre esses tipos, há aqueles denominados de "estudos de caso de organiza- ção numa perspectiva histórica" (BOGDAN; BIKLEN, 1994, p. 90), que são adequados ao objeto deste estudo, pela necessidade de divulgar a evolução de práticas avaliativas de uma dada instituição, ao longo do tempo.

De acordo com Yin (2001), o estudo de caso é uma estratégia apropriada para a apreciação de acontecimentos contemporâneos. De um modo geral, a condição de recenticidade dos acontecimentos requer dos avaliadores o reconhecimento do caso e seus significados, entremeado pelas variáveis de contexto, acompanhadas pelo possível interesse que despertem. O caso é descritivo quando apresenta um retrato pormenorizado de um dado fenômeno, conforme assinala Godoy (2006). Essas são situações que espelham o caso focalizado neste artigo.

Como pontua Stake, um dos precursores da utilização de estudos de caso em avaliação, o que os caracteriza "[...] não é uma escolha metodológica, mas uma escolha do objeto a ser estudado" (STAKE, 2000, p. 436). Assim, esse tipo de produção científica discute o que pode ser aprendido com um estudo de um único caso. Nesse sentido, o presente es-

8 A perícia metrológica é o "[...] conjunto de operações que tem por finalidade examinar e demonstrar as condições de um instrumento de medição e determinar suas características metrológicas de acordo com as exigências regulamentares aplicáveis" (INMETRO, 2007). Embora faça parte do controle metrológico legal, é uma atividade geralmente realizada por solicitação de órgãos do Poder Judiciário, para instrumentalização de processos judiciais.

Revista Brasileira de Monitoramento e Avaliação | Número 9 | Janeiro-Junho de 2015 
tudo parte da seguinte questão: o que pode ser aprendido com as práticas de avaliação adotadas pelo Inmetro para o processo de análise de demandas por regulamentação técnica metrológica?

Embora se faça alusão à relação entre a evolução das práticas de avaliação no Inmetro e à melhoria da gestão pública, este trabalho não busca fundamentar generalizações nesse sentido, mas sim compreender um caso particular. Dessa forma, conforme conceituação proposta por Stake (2000), caracteriza-se como estudo de caso intrínseco.

Para a elaboração deste trabalho foram considerados processos administrativos, relatórios técnicos e a norma interna que rege o processo de análise de demandas. A análise foi realizada tendo em vista os objetivos da avaliação, os procedimentos metodológicos utilizados, o nível de formalização da avaliação, o grau de participação dos stakeholders, os resultados das pesquisas avaliativas, as recomendações feitas pelos avaliadores, as decisões tomadas pela Diretoria de Metrologia Legal e a influência das recomendações dos avaliadores nessas decisões. Em seguida, os resultados obtidos foram analisados à luz da literatura selecionada.

\section{Resultados}

Em linhas gerais, a regulação é "[...] uma intervenção do Estado no funcionamento da sociedade ou da economia e se dá quando a ausência de intervenção pode resultar em prejuízos ou danos, ou pode comprometer o alcance dos objetivos legítimos" (BRASIL,
2007, p. 20). Para atingir esses objetivos (minimizar ou solucionar problemas na sociedade), o Estado pode empreender inúmeras ações, como o estabelecimento de regulamentos técnicos ${ }^{9}$. Assim, ainda que não tenha a natureza jurídica de agência reguladora, o Inmetro se vale de mecanismos regulatórios de "comando e controle" (BALDWIN; CAVE, 1999 apud LIMA, 2010, p. 20) ao elaborar regulamentos técnicos, fiscalizar os atores sociais e produtos sujeitos à regulamentação e aplicar penalidades nos casos de não conformidade.

O processo de análise de demandas começou a ser estruturado em 2009. Até então, a decisão de realizar o controle metrológico legal era baseada em critérios essencialmente técnicos, focados na necessidade de assegurar a credibilidade dos resultados das medições. As demandas eram apresentadas por qualquer segmento da sociedade, em especial fabricantes de instrumentos de medição e representantes do setor produtivo, e o Inmetro analisava a existência de infraestrutura necessária para executar o controle metrológico legal.

A estruturação do processo inseriu-se em um contexto mais amplo, no Brasil e no mundo, de busca pela melhoria da qualidade regulatória. Lima salienta:

Diante das evidências de que a regulação pode ensejar efeitos negativos, especialmente para o crescimento econômico, os governos têm-se debruçado na análise de impactos das políticas regulatórias. [...] De forma gradativa, governos e instituições multilaterais como a OCDE capitanearam essa orientação, seja do ponto 
de vista teórico ou da observação empírica, reunindo os ideários sob a forma de princípios, as chamadas best practices e better regulation, o que facilitou a sua utilização e consequente disseminação. (LIMA, 2010, p. 77).

Tendo como referências as melhores práticas regulatórias internacionais, expressas em relatórios da União Europeia e da Organização para a Cooperação e Desenvolvimento Econômico (OCDE), o Conselho Nacional de Metrologia, Normalização e Qualidade Industrial (Conmetro) publicou o Guia de Boas Práticas de Regulamentação, aprovado pela Resolução Conmetro nº 05/2007. O guia estabelece:

Boa regulamentação, implementada de maneira flexível, consistente, coerente e proporcional aos objetivos legítimos pretendidos é uma importante ferramenta para promover o desenvolvimento e o progresso da sociedade como um todo. Neste sentido, a adoção de boas práticas de regulamentação proporciona benefícios para a sua implementação, para a eficácia e eficiência da atuação do Estado no cumprimento dos seus objetivos legítimos, além de promover a cidadania, o progresso econômico e a minimização dos impactos ambientais, sociais e econômicos da regulamentação técnica. (BRASIL, 2007, p. 3).
O Guia de Boas Práticas de Regulamentação embasou a construção de mecanismos para avaliar as demandas por regulamentação técnica metrológica. Essa avaliação prevê a realização de análise de impacto regulatório (AIR) para estimar os possíveis efeitos da regulamentação, como sobre a capacidade produtiva do setor envolvido, aceitação/receptividade dos stakeholders à regulamentação proposta, possíveis externalidades negativas da regulamentação, entre outros fatores.

Em sua acepção clássica, a AIR é um método utilizado para estimar os impactos de uma dada intervenção do Estado, com foco em técnicas como a análise de custo/benefício, análise de custo/efetividade e análise de riscos. A AIR tem como objetivo:

[...] fornecer informações às autoridades regulamentadoras que possibilitem antever as consequências da implementação da regulamentação técnica e subsidiem o processo decisório da sua concepção e adoção. Desta maneira, a Avaliação do Impacto da Regulamentação é uma ferramenta fundamental para que sejam elaboradas boas regulamentações técnicas, que atendam aos objetivos pretendidos com os menores impactos possíveis. (BRASIL, 2007, p. 26). 


\section{- QUADRO 1: CRITÉRIOS DO PROCESSO DE ANÁLISE DE DEMANDAS POR REGULAMENTAÇÃO TÉCNICA METROLÓGICA}

\begin{tabular}{|c|c|c|}
\hline CATEGORIAS & INDICADORES & PADRÕES DE AVALIAÇÃO \\
\hline \multirow{2}{*}{$\begin{array}{l}\text { Representatividade das } \\
\text { partes interessadas na } \\
\text { avaliação }\end{array}$} & Taxa de resposta ao questionário & $\begin{array}{l}\text { Abaixo de } 25 \% \text { : representatividade baixa. } \\
\text { Acima de } 25 \% \text { : representatividade adequada. }\end{array}$ \\
\hline & $\begin{array}{l}\text { Quantidade de participantes de } \\
\text { cada um dos segmentos das par- } \\
\text { tes interessadas }\end{array}$ & $\begin{array}{l}\text { Pelo menos um representante de cada segmento } \\
\text { identificado: quantidade adequada. }\end{array}$ \\
\hline \multirow{2}{*}{$\begin{array}{l}\text { Percepção das partes in- } \\
\text { teressadas }\end{array}$} & $\begin{array}{l}\text { Grau de severidade de risco do } \\
\text { cenário atual /avaliação do risco } \\
\text { (AR) na percepção dos respon- } \\
\text { dentes }\end{array}$ & $\begin{array}{l}A R \leq 6 \text { : risco baixo/ não justifica intervenção. } \\
8 \leq A R \leq 12 \text { : risco moderado/ justifica intervenção } \\
\text { não imediata. } \\
A R \geq 15 \text { : risco crítico/ justifica intervenção imediata. }\end{array}$ \\
\hline & $\begin{array}{l}\text { Interesse dos stakeholders pela } \\
\text { regulamentação }\end{array}$ & $\begin{array}{l}\text { Opinião em consenso favorável à regulamentação: } \\
\text { justifica intervenção. } \\
\text { Opinião em consenso desfavorável à regulamenta- } \\
\text { ção: não justifica intervenção. }\end{array}$ \\
\hline
\end{tabular}

Fonte: os autores (2014).

A metodologia de AIR começou a ser adequada e implementada ao processo de regulamentação técnica metrológica a partir de 2009. No início, o trabalho centrou-se na construção de instrumentos para uma avaliação inicial (uma espécie de triagem) das demandas por regulamentação recebidas, com a intenção de excluir as que não atendessem aos critérios definidos e priorizar as restantes.

As primeiras pesquisas de opinião foram realizadas em 2011, por meio de questionário online enviado diretamente ao e-mail de representantes das partes interessadas. $\mathrm{O}$ instrumento de avaliação passou por processo de validação de conteúdo com especialistas da Diretoria de Metrologia Legal antes de começar a ser aplicado.

O cadastro de respondentes foi composto por 53 pessoas do setor produtivo, usuários dos instrumentos de medição, consumidores, órgãos de governo e entidades de classe. A taxa média de resposta foi de $51 \%$. Os questionários foram compostos de questões fechadas de múltipla escolha, abertas e mistas, que versavam sobre os seguintes aspectos: danos esperados pela ausência de controle do Inmetro sobre o instrumento de medição em questão; impactos esperados do regulamento proposto; interesse e receptividade dos demais segmentos econômicos ao regulamento; e infraestrutura existente para a implantação do regulamento. Nesse período, o processo não era completamente formalizado, mas os resultados foram repassados para a diretoria em reuniões de coordenação. As recomendações foram acatadas, e os resultados foram utilizados para a priorização dos projetos de regulamentação.

Em 2012 foram avaliadas quatro demandas por regulamentação, sendo três por meio de questionário e uma em painel setorial. Em três dos casos, a situação era de ausência de regulamentação; no outro, o regulamento em 
vigor foi considerado defasado por um dos segmentos afetados.

A equipe começou a desenvolver critérios para as avaliações, mas que não chegaram a ser totalmente formalizados. Após a apreciação dos relatórios técnicos, foi possível codificar as categorias de análise, indicadores e padrões no Quadro 1.

No caso da demanda tratada em painel setorial, a avaliação foi realizada de forma essencialmente qualitativa. Os stakeholders foram identificados em pesquisa interna, com o auxílio de especialistas na área, e compuseram a listagem de convidados para o evento. A equipe teve o cuidado de montar um painel de debates equilibrado, garantindo a expressão de opiniões divergentes entre os palestrantes. Os padrões estipulados para representatividade e percepção dos stakeholders foram satisfeitos e compuseram as recomendações dos avaliadores (INMETRO, 2012).

No caso das avaliações feitas por meio de questionários, a taxa média de resposta foi de aproximadamente $24 \%$, para um total de 80 consultados. Os instrumentos de avaliação foram reformulados, buscando maior alinhamento às necessidades da pesquisa avaliativa (ELLIOT; HILDENBRAND; BERENGER, 2012). Foram inseridas questões que buscavam mensurar o risco do cenário do momento em que foi realizada a avaliação. A metodologia foi baseada em estudo realizado para a Diretoria de Avaliação da Conformidade do Inmetro (CEPEA-ESALO/FEALO; INMETRO, 2009) e adaptado às especificidades da metrologia legal.

A mensuração do risco foi realizada por meio de duas questões: uma se referia às consequências do problema, e outra, à probabilidade de sua ocorrência. Para cada questão foram apresentadas cinco opções de resposta em uma escala nominal. Na questão relativa às consequências do problema, foram oferecidas opções com gradação de "catastrófica" a "insignificante"; com relação à probabilidade de ocorrência, as opções foram de "quase certo" a "raro". Para minimizar divergências de interpretação, cada opção de resposta foi apresentada com definições precisas. A gradação correspondia a um valor numérico de um a cinco para cada opção, que não foi informado ao respondente. $\mathrm{O}$ grau de risco foi obtido com a multiplicação dos valores atribuídos a cada resposta, resultando nas classificações mencionadas no Quadro 1.

Além da mensuração de risco, outras inovações ocorridas nesse ano foram a formalização da avaliação em processos administrativos e a padronização dos relatórios técnicos. Esses relatórios comunicavam os resultados à diretoria e apresentavam recomendações.

Revista Brasileira de Monitoramento e Avaliação | Número 9 | Janeiro-Junho de 2015 
Três das recomendações foram aceitas integralmente, e uma propiciou pedidos de nova avaliação por conta da baixa taxa de resposta.

Nos anos seguintes, as avaliações foram aperfeiçoadas, especialmente no que tange à identificação de stakeholders e aos procedimentos metodológicos. Em 2013, foram realizadas duas avaliações por meio de questionário e um painel setorial (INMETRO, 2013). Foram obtidas mais de 1.000 respostas nos surveys, com questionários customizados para os diferentes segmentos das partes interessadas. Além de metodologia quantitativa (grau de severidade de risco), foram utilizados questionários diferentes para cada segmento consultado, com abordagem qualitativa.

Para a identificação dos palestrantes e dos convidados do painel setorial foram utilizados os mesmos mecanismos de pesquisa interna com o apoio de especialistas, além de consulta à Ouvidoria do Inmetro. As recomendações finais de 2013 foram aceitas totalmente para os três casos.

Em 2014 foi realizada uma análise de demanda com pesquisa de opinião e mensuração do grau de severidade de risco. Para ampliar ainda mais o número de respondentes das pesquisas, a equipe passou a ter acesso a novas bases de dados, como a Relação Anual de Informações Sociais (RAIS) do Ministério do Trabalho e Emprego. Foram elaborados questionários para dois segmentos distintos dentre as partes interessadas. Um questionário foi endereçado aos stakeholders identificados em pesquisa na RAIS, totalizando mais de 45 mil pessoas em todo o país. O outro foi enviado às partes interessadas identificadas de forma tradicional, com pesquisa feita pelos avaliadores do Inmetro, totalizando 67 pessoas. A taxa de resposta para ambos os questionários foi bastante peculiar: 0,08\% ${ }^{10}$ para a base da RAIS e 23,88\% para a base tradicional.

No mesmo ano, a equipe elaborou norma interna para disciplinar as metodologias possíveis de avaliação. Os critérios mencionados no Quadro 1 continuaram a ser utilizados, mas apenas os padrões para o grau de severidade de risco foram mencionados na norma.

Foram inseridos novos itens de análise e elaborado um checklist informal para guiar o trabalho dos avaliadores. Além das análises de demanda estudadas neste artigo, também são realizadas avaliações baseadas apenas no atendimento de itens previstos no checklist. Geralmente, essa metodologia é utilizada em casos de urgência ou nos quais existe pouca informação sobre a demanda. O checklist contém as principais perguntas a serem respondidas pela equipe de análise de demandas. Em muitos casos, as recomendações são sugeridas após a análise das informações pesquisadas.

\section{Discussão}

Os principais resultados deste estudo podem ser ilustrados no Quadro 2 ao lado. 


\section{- OUADRO 2: SÍNTESE DA EVOLUÇÃO DO PROCESSO DE ANÁLISE DE DEMANDAS POR REGULAMENTAÇÃO TÉCNICA METROLÓGICA (2011 A 2014)}

\begin{tabular}{|c|c|c|c|c|}
\hline \multirow{2}{*}{$\begin{array}{l}\text { ASPECTOS } \\
\text { AVALIADOS }\end{array}$} & \multicolumn{4}{|c|}{ REALIZAÇÕES POR ANO } \\
\hline & 2011 & 2012 & 2013 & 2014 \\
\hline $\begin{array}{l}\text { Análises estudadas neste } \\
\text { artigo }\end{array}$ & Duas & Quatro & Três & Uma \\
\hline Objetivos da avaliação & $\begin{array}{l}\text { Avaliar impactos } \\
\text { socioeconômicos } \\
\text { e ambientais da } \\
\text { regulamentação }\end{array}$ & $\begin{array}{l}\text { - Identificação do } \\
\text { problema. } \\
\text { - Análise de risco. }\end{array}$ & $\begin{array}{l}\text { - Identificação do } \\
\text { problema. } \\
\text { - Análise de risco. } \\
\text { - Análise de cenários. }\end{array}$ & $\begin{array}{l}\text { - Identificação do } \\
\text { problema. } \\
\text { - Análise de risco. }\end{array}$ \\
\hline $\begin{array}{l}\text { Procedimentos metodo- } \\
\text { lógicos }\end{array}$ & $\begin{array}{l}\text { Questionários online } \\
\text { enviados a pessoas } \\
\text { da base cadastral }\end{array}$ & $\begin{array}{l}\text { - Questionários } \\
\text { online enviados a } \\
\text { pessoas da base } \\
\text { cadastral. } \\
\text { - Painel setorial. }\end{array}$ & $\begin{array}{l}\text { - Questionários online } \\
\text { enviados a pessoas da } \\
\text { base cadastral. } \\
\text {-.Survey com questio- } \\
\text { nário hospedado no } \\
\text { site do Inmetro. } \\
\text {-.Survey por call } \\
\text { center. } \\
\text { - Painel setorial. }\end{array}$ & $\begin{array}{l}\text { - Questionário } \\
\text { online enviado a } \\
\text { pessoas da base } \\
\text { cadastral e da } \\
\text { RAIS. }\end{array}$ \\
\hline Formalização da avaliação & Não & $\begin{array}{c}\text { Processos adminis- } \\
\text { trativos }\end{array}$ & $\begin{array}{c}\text { Processos adminis- } \\
\text { trativos }\end{array}$ & $\begin{array}{c}\text { Processo adminis- } \\
\text { trativo }\end{array}$ \\
\hline $\begin{array}{l}\text { Participação dos stakehol- } \\
\text { ders }\end{array}$ & $\begin{array}{l}\text { - } 53 \text { consultados. } \\
\text { - Taxa média de } \\
\text { resposta: } 51 \text { \%. }\end{array}$ & $\begin{array}{l}\text { - } 80 \text { consultados } \\
\text { (três pesquisas). } \\
\text { - Taxa média de } \\
\text { resposta: } 24 \% \text {. } \\
\text { - } 77 \text { presentes no } \\
\text { painel setorial. }\end{array}$ & $\begin{array}{l}\text { - Questionários online: } \\
\text { taxa média de respos- } \\
\text { ta de } 15 \% \text {. } \\
\text { - Survey online: } 1.001 \\
\text { respostas. } \\
\text { - Survey por call cen- } \\
\text { ter: } 663 \text { respostas. } \\
\text { - } 52 \text { presentes no } \\
\text { painel setorial. }\end{array}$ & $\begin{array}{c}\text { Survey (base } \\
\text { RAIS): } 45.265 \\
\text { consultados. } \\
\text { - Taxa de resposta: } \\
\text { 0,08\%. } \\
\text { Base cadastral: } \\
\text { - } 67 \text { pessoas. } \\
\text { - Taxa de resposta: } \\
23,88 \% .\end{array}$ \\
\hline $\begin{array}{l}\text { Influência das recomenda- } \\
\text { ções na tomada de decisão }\end{array}$ & $\begin{array}{c}\text { Recomendações } \\
\text { acatadas nos dois } \\
\text { casos. }\end{array}$ & $\begin{array}{l}\text { Recomendações } \\
\text { acatadas em três } \\
\text { dos casos. }\end{array}$ & $\begin{array}{c}\text { Recomendações } \\
\text { acatadas nos quatro } \\
\text { casos. }\end{array}$ & $\begin{array}{c}\text { Recomendações } \\
\text { acatadas. }\end{array}$ \\
\hline
\end{tabular}

Fonte: os autores (2015).

10 A baixa taxa de resposta foi atribuída pela equipe à seleção dos respondentes e ao próprio instrumento de medição pesquisado, cujo uso é restrito a um público bem específico. Os contatos cadastrados na base da RAIS são e-mails dos contadores das empresas e não das empresas em si. Assim, concluiu-se que a sua utilização deve ocorrer apenas nas pesquisas sobre instrumentos de medição mais conhecidos do público em geral.

Revista Brasileira de Monitoramento e Avaliação | Número 9 | Janeiro-Junho de 2015 
Além de deter a estrutura regulatória e de law enforcement em metrologia legal, o Inmetro também é responsável por elaborar regulamentos técnicos na área de avaliação da conformidade. Na estrutura organizacional, a avaliação da conformidade é uma diretoria própria, com procedimentos e normas específicas. Assim, este artigo não apresenta todas as práticas de avaliação do Inmetro no processo de regulamentação técnica; apenas aquelas realizadas na Diretoria de Metrologia Legal.

Este estudo não teve a pretensão de esgotar as relações possíveis entre as práticas de avaliação do Inmetro e a literatura na área, mas espera contribuir com a reflexão sobre a importância da avaliação na gestão pública. Para os autores, a relevância deste estudo reside na demonstração prática de construção de conhecimento organizacional e na importância da lógica da avaliação nos processos de trabalho.

De forma geral, o processo de análise de demandas busca identificar os seguintes aspectos: a. interesse dos setores envolvidos na regulamentação;

b. legislação relacionada (do Inmetro e de demais órgãos regulamentadores);

c. base normativa;

d. impactos sociais, econômicos e ambientais da regulamentação;

e. grau de severidade de risco associado ao problema identificado;

f. cenário político e econômico do país;

g. aspectos específicos da demanda, como melhores práticas internacionais.

Em qualquer que seja a metodologia utilizada, a análise da demanda é pautada pelos princípios fundamentais de qualquer avaliação (cf. PENNA FIRME; LETICHEVSKY, 2010): utilidade, por buscar as informações consideradas importantes pela administração; viabilidade, com a utilização dos recursos de forma realista e simples; ética, garantindo participação equilibrada dos stakeholders com interesses diversos e observando o sigilo das respostas nas pesquisas; e precisão, demonstrando como os julgamentos foram realizados. 
As avaliações realizadas no processo de análise de demandas têm como objetivo primordial subsidiar a tomada de decisões por parte da administração do Inmetro. Dessa forma, classificam-se, quanto à abordagem, como avaliações centradas na administração, conforme definido por Worthen, Sanders e Fitzpatrick (2004).

Com relação ao momento em que ocorrem, são avaliações ex-ante, pois acontecem antes da aprovação do programa. Sobre este tipo de avaliação, Rua afirma:

Sendo um instrumento de apoio ao processo decisório, a avaliação ex-ante ocorre antes da decisão sobre como será feita uma intervenção, ao longo da formulação da policy, e não antes de a implementação, de fato, tornar-se realidade. Esse tipo de avaliação tem natureza "formativa"; integra as discussões em torno da formulação das alternativas de solução; e envolve a tomada de decisão, informando sobre os seus riscos e as suas limitações, as vantagens a maximizar, a consistência entre objetivos e meios, a viabilidade e suficiência dos insumos, a pertinência das soluções à esfera de atuação das organizações abarcadas na intervenção pretendida, entre outros. Há alguns tipos de avaliação ex-ante, a depender, mais uma vez, do critério adotado. Ela pode focalizar, por exemplo, a situação-problema que a política pública deseja solucionar (avaliação ex-ante de situação), ou o desenho e as articulações do projeto da política pública (avaliação ex-ante de projeto ou de estrutura), entre muitas outras categorias. (RUA, 2014, p.17-18).

Sob o aspecto da procedência dos avaliadores, classificam-se como avaliações internas, pois são executadas por servidores do Inmetro não diretamente responsáveis pela implementação do programa (ANGUERA; CHACÓN, 2008).

A análise de demandas busca identificar a real necessidade de atuação do Inmetro em algum problema da sociedade. Para isso é necessário estudar a fundo o problema apresentado e identificar melhores práticas em cada área. Dessa forma, conforme definido por Owen (2007), essas avaliações configuram-se como proativas.

Foi possível perceber que as recomendações embasadas em resultados de surveys ou da discussão de painéis setoriais tiveram maior aceitação no processo decisório, demonstrando a preocupação com a objetividade dos processos, transparência das ações e precisão dos resultados.

Revista Brasileira de Monitoramento e Avaliação | Número 9 | Janeiro-Junho de 2015 


\section{Conclusões}

As análises de demanda estudadas neste artigo foram desenhadas de forma a enfatizar a participação das partes interessadas no processo de avaliação. Além de ilustrar o esforço da instituição em se aproximar das necessidades dos cidadãos, esta prática permite antever problemas que podem ocorrer com a regulamentação, como a distribuição desigual de seus efeitos (BRASIL, 2007). A participação dos stakeholders no processo decisório, ainda que de caráter consultivo, favorece a adoção do regulamento por esses mesmos segmentos, pois permite que se apropriem das decisões da instituição.
Como mencionado anteriormente, as avaliações no Inmetro sempre resultam em relatórios com recomendações de ação para a Diretoria de Metrologia Legal. A análise desse processo permitiu perceber que a maioria das recomendações foi aceita pela administração, sendo que as não aprovadas integralmente serviram de base para intensas discussões, que originaram novas ideias e soluções de problemas.

Embora tenham apresentado uma clara evolução nos últimos anos, as avaliações reali- 
zadas pelo Inmetro ainda enfrentam muitos desafios. Em primeiro lugar, destaca-se a dificuldade de identificação e engajamento das partes interessadas no processo de análise de demandas. De poucas dezenas para dezenas de milhares, a base de consultados foi bastante ampliada, mas o processo ainda carece de participação representativa da população, pois as taxas de resposta ainda são baixas e muitas vezes não significativas.

A capacitação dos profissionais envolvidos no processo é outro desafio para a melhoria contínua das avaliações. Apesar do apoio da instituição, a oferta de cursos e treinamentos na área ainda é bastante escassa no Brasil.

De todo modo, as experiências em avaliação no Inmetro demonstram a importância dessa disciplina e profissão na melhoria da gestão pública do país. No caso específico do processo de regulamentação, a avaliação tem contribuído para uma tomada de decisão cada vez mais fundamentada, respondendo às necessidades de atuação da instituição em cenários complexos. 
ALVES-MAZZOTTI, Alda Judith. Usos e abusos dos estudos de caso. Cadernos de Pesquisa, São Paulo, v. 36, n. 129, p. 637-651, dez. 2006. Disponível em: <http://www.scielo.br/ scielo.php?script $=$ sci_arttext\&pid $=$ S0100$-15742006000300007 \&$ lng $=p t \& n r m=i s o>$. Acesso em: 05 jul. 2014.

ANGUERA, M. T.; CHACÓN, S. Aproximación conceptual en evaluación de programas. In: ANGUERA, M. T.; CHACÓN, S.; BLANCO, A. Evaluación de programas sociales y sanitarios: un abordaje metodológico. Madrid: Síntesis, 2008. p. 17-36.

BOGDAN, R.; BIKLEN, S. Investigação qualitativa em educação. Porto: Porto Editora, 1994.

BRASIL. Presidência da República. Lei nº 9.933 , de 20 de dezembro de 1999. Dispõe sobre as competências do Conmetro e do Inmetro, institui a Taxa de Serviços Metrológicos, e dá outras providências. Diário Oficial da República Federativa do Brasil. Brasília, DF, 21 dez. 1999.

CEPEA-ESALO/FEALO; INMETRO. Estudo sobre metodologia de quantificação e qualificação de impactos econômicos, sociais e ambientais de programas de avaliação da conformidade. Piracicaba, 2009.

CONSELHO NACIONAL DE METROLOGIA, NORMALIZAÇÃO E OUALIDADE INDUSTRIAL (CONMETRO). Guia de Boas Práticas de Regulamentação anexo à Resolução Conmetro 05/2007. Diário Oficial da União da República Federativa do Brasil. Brasília, DF, n. 244, 20 dez. 2007. Seção 1, p. 116. Disponível em: <http://www.inmetro. gov.br/legislacao/consulta.asp?seq_classe=7>. Acesso em: 16 jun. 2014.
ELLIOT, Ligia Gomes; HILDENBRAND, Luci; BERENGER, Mercêdes Moreira. Questionário. In: ELLIOT, Ligia Gomes et al. Instrumentos de avaliação e pesquisa: caminhos para construção e validação. Rio de Janeiro: Wak Editora, 2012.

GODOY. A. S. Estudo de caso qualitativo. In: GODOI, C. K.; BANDEIRA DE MELO, R.; SILVA, A. $B$ (Orgs.). Pesquisa qualitativa em estudos organizacionais: paradigmas, estratégias e métodos. São Paulo: Saraiva, p. 115-146, 2006.

INSTITUTO NACIONAL DE METROLOGIA, OUALIDADE E TECNOLOGIA (INMETRO). Metrologia Legal. Inmetro, [s. l., s. d.]. Disponível em: <http://www. inmetro.gov.br/metlegal/>. Acesso em: 16 jun. 2014.

Relato técnico. Rio de Janeiro, 2012. Disponível em: <http://www.inmetro.gov. br/painelsetorial/palestras/relato_tecnico_ efluentes.pdf>. Acesso em: 10 out. 2014.

Relato técnico. Rio de Janeiro, 2013. Disponível em: <http://www.inmetro.gov.br/ painelsetorial/palestras/relato-tecnico-medicao-leite.pdf>. Acesso em: 10 out. 2014.

Vocabulário internacional de termos de metrologia legal: portaria INMETRO $n^{\circ} 163$ de 06 de setembro de 2005 / INMETRO, SENAI - Departamento Nacional. 5. ed. Rio de Janeiro: Ed. SENAI, 2007.

INTERNATIONAL ORGANIZATION OF LEGAL METROLOGY (OIML). Benefit of Legal Metrology for the Economy and Society (John Birch). Expert Report OIML E2 Edition 2003. Disponível em: < https://www.oiml.org/en/publications/ expert/publication_view?p_type=78p_status=1>. Acesso em: 29 jun. 2015. 
Considerations for a Law on Metrology. Considérations pour une Loi de Métrologie. International Document: OIML D1 Edition 2012. Disponível em: <https://www.oiml.org/ en/publications/documents/publication view?p_type $=2 \varepsilon p \_s t a t u s=1>$. Acesso em: 29 jun. 2015.

Principles of metrological supervision. Principes de la surveillance métrologique. International Document: OIML D9 Edition 2004. Disponível em: <https://www.oiml.org/ en/publications/documents/publication view?p_type=28p_status=1>. Acesso em: 29 jun. 2015.

LIMA, Valéria Athayde Fontelles de. A Avaliação de Impacto Regulatório e sua aplicação no Brasil. Rio de Janeiro, 2010, 156 f. (Dissertação (Mestrado em Políticas Públicas, Estratégias e Desenvolvimento)-Instituto de Economia, Universidade Federal do Rio de Janeiro).

OWEN, J. M. Program Evaluation: forms and approaches. New York: The Guilford Press, 2007.
PENNA FIRME, Thereza; LETICHEVSKY, Ana Carolina. O desenvolvimento da capacidade de avaliação no século XXI: enfrentando o desafio através da meta-avaliação. Meta: Avaliação, Rio de Janeiro, v. 2, n. 5, p. 180-195, maio/ago. 2010.

RUA, Maria das Graças. Avaliação de políticas públicas e programas governamentais. Brasília: Instituto de Gestão, Economia e Políticas Públicas, 2014.

SILVA, Jorge Kenedy Almeida. Regulamentação técnica: proposição de um código mínimo das boas práticas e diagnóstico do sistema brasileiro. Rio de Janeiro, 2007, 185 f. (Dissertação (Mestrado em Metrologia)-Pontifícia Universidade Católica do Rio de Janeiro, Rio de Janeiro, 2007).

STAKE, Robert E. Case studies. In: DENZIN, N. K.; LINCOLN, Y. S. (Ed.). Handbook of qualitative research. London: Sage, 2000. p. 435-454.

WORTHEN, B. R.; SANDERS, J. R.; FITZPATRICK, J. L. Avaliação de programas: concepções e práticas. São Paulo: Ed. Gente, 2004.

YIN, R. K. Estudo de caso: planejamento e métodos. 2. ed. Porto Alegre: Bookman, 2001.

Revista Brasileira de Monitoramento e Avaliação | Número 9 | Janeiro-Junho de 2015 